\title{
Personal Autonomy in Society
}

Marina Oshana

Ashgate, Aldershot, 2006, 204pp.

ISBN: 0754656705.

Contemporary Political Theory (2007) 6, 492-496. doi:10.1057/palgrave.cpt.9300313

Debates concerning individual autonomy have, it seems, spilled out of the lecture theatre and entered the legislative assemblies and government departments of many liberal democratic states throughout the world. Many of the most pressing political questions currently facing the governments of the UK and the US, for example, are questions concerning autonomy — its limits, its importance, how it might be protected, and how and when it might be taken away. The 'war on terror' currently being waged by the US and the UK has provided the justification for a raft of new measures aimed at protecting national security which have led citizens, legislators, and academics to confront difficult questions about the nature of freedom and the responsibilities of liberal states. While human rights activists criticize the moves made, for example, in the US Patriot Act and the British Anti-Terrorism Act, defenders argue that some erosion of autonomy is a necessary and inevitable price to pay for increased national security. According to the Associated Press, one-third of Americans currently 'favour making it easier for authorities to access private e-mail and phone conversations [and] more than 70 percent favour requiring US citizens to carry identification cards with fingerprints' (p. 135). Evidence such as this would appear to suggest that such measures are not always the draconian impositions that many rights activists make them out to be, but instead represent a response to genuinely felt, democratically expressed sentiments among wide sections of the political community. Should these democratically expressed concerns pass into laws that undermine individual autonomy? The answer to this question depends on how (and to what extent) one values democracy. It also depends on what one means by autonomy.

Marina Oshana says little about democracy in her book, but a lot about autonomy. Oshana notes the apparent erosion of individual autonomy in many Western democracies. She encourages us to return to fundamental debates about the nature and value of autonomy in liberal democratic states, and to reflect upon the extent to which the autonomy of the individual might be fostered in a wider climate of political uncertainty. What is autonomy? What is it not? And how - and to what extent - might social and political institutions protect autonomy while at the same time protecting other values such as security?

Oshana confronts these questions head on. In Personal Autonomy in Society Oshana develops a coherent and persuasive account of personal autonomy, 
and a thoroughgoing defence of why autonomy thus understood should be valued. Her central question might be said to be a common one in analytical philosophy and in Anglo-American political theory: how can we be understood to be autonomous (in the sense that we have de facto control over our lives) given that 'our character and our values are, in part, shaped unbidden and that the processes by which these are shaped begins before we are in a position to chart the course of our lives' ( $p$. 158). That is, how can we be understood as autonomous when so much of our lives are determined for us by relationships and attachments over which we have little or no control?

Oshana's account of autonomy is rooted in the idea that social relations matter, and matter profoundly. Our autonomy will be shaped, constrained and limited by the relationships in which we are, and have been, engaged. Autonomy is therefore not merely a condition of psychological authenticity (as thinkers like Frankfurt and Dworkin have argued); rather it describes the individual's capacity to deliberate upon the content of her life and to 'change her values and motivations and to alter significant relations in her life if she so chooses' (p. 159). For Oshana, autonomy does not merely describe a 'state of mind', or an 'inner citadel' of core reason, but rather a historically and socially shaped capacity to achieve 'substantive independence' from persons, values, and roles which are inhospitable to one's capacity for self-government.

The account of autonomy Oshana provides, then, is therefore both 'socialrelational' and perfectionist. The capacity for an individual to be autonomous is shaped by the definite social conditions in which she finds herself. But not all social relationships will be conducive to autonomy. Some may deny or erode her capacity for self-government, and it is important that she is protected from such relationships in order that her autonomy is encouraged. An important normative implication of this claim, of course, is that state institutions have a responsibility to encourage certain kinds of social relations (and the ways of life to which they give rise) at the expense of others which are not compatible with personal autonomy.

Oshana rightly acknowledges that this leads her into controversial territory. The idea that the state has a responsibility to encourage certain ways of life at the expense of others represents a fundamental challenge to many liberals who believe that social and political institutions should seek to be impartial among different conceptions of the good life. In particular, she argues, her claims put her at odds with defenders of classical liberalism or libertarianism, for whom the exercise of free choice is more important than questions concerning the origins of these choices. Oshana's theory specifically argues that certain conditions need to hold in order for an individual's choices to be understood as autonomous - conditions internal to the individual (such as rationality, procedural independence, and self-respect), and social and political conditions 
external to the individual (such as access to a range of options, financial security, freedom from misinformation, and a general system of institutions capable of securing all these things). In doing so, her theory underwrites a perfectionist account of politics aimed at encouraging those social and political conditions in which individuals might genuinely take control of their lives with the help of active state institutions committed to encouraging this substantive ability in all people.

Oshana presents all this in an engaging and precise manner. In testing her theory against a number of 'hard cases', she successfully outlines her case against the structuralists and shows the perfectionist nature of autonomy as rooted in certain autonomy-supportive social conditions. The question that remains, however, is whether her theory is as controversial or as unique as she seems to think it is. She is indeed right that many liberal political theorists would reject her argument for perfectionism, but she neglects to discuss in any great depth the fact that many others would embrace it as a fundamental normative foundation for understanding the roles and responsibilities of the state. Liberals are, of course, split over many things, and the extent to which liberal principles and institutions should remain impartial with regard to different conceptions of the good life represents perhaps the most obvious fault line within the doctrine. While Oshana rightly points out that her theory will be controversial among impartialists, she seems unwilling to acknowledge that it will not be all that controversial at all among a growing and influential group of thinkers who believe that liberalism should actively seek to foster autonomy supportive conditions in society at the expense of those conditions which are inimical to autonomy.

Oshana seems insufficiently attentive to (or merely unaware of) the disagreements which rage among liberals on this and other questions, and too quick to assume that the governments of actually existing liberal states can be evaluated as exemplars of liberalism as found in academic discourse. For example, in Chapter 5 (in which she discusses a number of 'objections from liberalism' to her theory), she states that there 'is good reason to believe that political liberals value a perfectionist notion of autonomy. In the liberal society of the US, the government does claim that some ways of life are inherently superior to others and frequently aims to promote some ways of life over others' (p. 105). There are several problems with this. Primarily, it is not entirely clear what relationship the current US government has with 'political liberalism'. It would seem that what Oshana means by 'political liberalism' is merely 'the project of using liberal theory to inform a set of guiding values for our social and political institutions'. Consequently, she is not talking about 'political liberalism' of the kind that dominates contemporary debates in Anglo-American political theory (i.e. as defined by thinkers such as John Rawls and Charles Larmore), and hence, she is using the term in a way that will 
appear slightly alien and confusing to many readers. More importantly, she seems unaware that this might be significant.

It is significant, however, because it makes locating her work in the wider literature a little difficult, and also leads her to make certain problematic claims. This is most obvious when she comes to defend her position 'against' liberals. 'There is nothing inconsistent about holding a perfectionist account of autonomy in conjunction with political liberalism', she argues. Indeed, 'Stephen Wall defends a perfectionist variety of liberalism' (p. 105). This is true. But Wall is not a political liberal. His liberalism is rooted in a perfectionist defence of personal autonomy which specifically stands in contradiction to political liberalism. Joseph Raz, Will Kymlicka, John Stuart Mill, and many others have also argued that liberals should seek to root liberalism in the principle of autonomy rather than a strict impartialism, and they have done so by drawing a distinct line between themselves and those defenders of 'political liberalism' who are in general sceptical of the compatibility of personal autonomy with other important liberal values such as stability and toleration. Political liberalism of the kind that most political theorists working in this area would recognize has risen in popularity precisely because it rejects the claim that liberalism should be concerned with the encouragement of certain ways of life over others.

It is an open and important question whether political liberalism of the Rawlsian/Larmorean variety might be said to lean more heavily on the principle of autonomy than its advocates believe. But this issue is not discussed in the book, and no suggestion is made that different forms of liberalism might hold really quite divergent views on the structure and ends of liberal political theory. Consequently, the conclusion that Oshana asks us to accept is that liberalism - broadly conceived - is not necessarily incompatible with the idea of personal autonomy. This is true but would not, I suggest, come as news to many.

Oshana is indeed right in her claims that liberal perfectionism is a controversial doctrine. It is controversial in the Rawlsian sense (that it represents a comprehensive account of the good which not everyone will share), and in the broader sense that it will be rejected by many within and outside the liberal tradition. Oshana's book is a work of philosophy rather than political theory, and so her concern is to work out what autonomy is, not whether it might be consistent with the kind of value pluralism that characterizes contemporary liberal democratic states. Indeed, she suggests that many political theorists who claim to be interested in getting to grips with the nature of autonomy are not really interested in doing so at all. Oshana suspects that "philosophers who insist upon deciding the merit of an account of autonomy by seeing what the account would imply for political concerns such as the shape of liberal principles and the validation of such principles are not 
concerned with autonomy but with political theory and what best comports with presuppositions embedded in the theory' (p. 74). Maybe. But for someone who seems at least partially motivated by a desire to defend not only a particular definition of autonomy but the value of autonomy in the face of increased attacks by governments throughout the world, she must be concerned, surely, whether her account of autonomy is politically attainable, and what a theory needs to look like in order for it to be a plausible response to concrete political problems. Political theory does not strike me as an enemy of philosophical rigour, here. Rather it strikes me as a process of working out exactly how much of a pure account like this we might hope for in a world in which (as she rightly points out) individuals seem more and more willing to give up some of their autonomy in order to feel more secure, more unified as a society, more inclusive, or simply less afraid.

Philip Parvin

Trinity Hall, Cambridge, UK

Negotiating Diversity: Liberalism, Democracy and Cultural Difference

Matthew Festenstein

Polity Press, Cambridge, 2005, 197pp.

ISBN: 9780745624068.

Contemporary Political Theory (2007) 6, 496-497. doi:10.1057/palgrave.cpt.9300312

This is a very welcome survey of current debates in political philosophy about multiculturalism. It is welcome not only for providing an intelligible, dispassionate and illuminating summary of the very heterogeneous contributions to these debates but also for its timeliness. Now seems a very good moment indeed to be clear about the politics of cultural difference. Multiculturalism has been a hot topic in political philosophy since Kymlicka's first book in 1989; it is now and for all the self-evident reasons a hot political topic.

The book is clearly written, is thorough in its treatment of various claims and displays an impressive familiarity with a wealth of material. At the same time Festenstein presses his own particular viewpoint without letting that get in the way of a fair-minded treatment of all the usual suspects: Brian Barry, Will Kymlicka, Chandran Kukathas and Charles Taylor. Brian Barry in particular is cut down to size and plausibly exposed as far less of an intellectual threat to the politics of multiculturalism than his own rhetoric suggests. 